International Journal of Engineering \& Technology, $7(1.5)(2018) 258-263$
International Journal of Engineering \& Technology
SPC
Website: www.sciencepubco.com/index.php/IJET
Research paper

\title{
FEM method structural analysis of pressure hull by using hyper mesh
}

\author{
V.Balaji ${ }^{1 *}$, S. Ravi ${ }^{2}$, P.Naveen Chandran ${ }^{3}$ \\ ${ }^{I}$ Research scholar, Department of Mechanical Engineering, \\ Bharath Institute of Higher Education And Research ( BIHER ), Chennai, India. \\ ${ }^{2}$ Professor, Department of Mechanical Engineering, Sriram College of Engineering, Chennai, India. \\ ${ }^{3}$ Professor, Department of Automobile Engineering, \\ Bharath Institute of Higher Education And Research ( BIHER ), Chennai, India. \\ *Corresponding author E-mail: v.balaji_b1980@yahoo.co.in
}

\begin{abstract}
Pressure hulls are the central load bearing structures of naval submarines, and AUVs ( autonomous underwater vehicles).. A pressure hull is a structure that is designed to resist the compressive forces related with hydrostatic pressure. The most coherent geometries for resisting these compressive forces are annular cross-sections, and thus, pressure hulls are typically composed of a combination of cones and ring-stiffened cylinders, with torispherical domes or spherical at either end. These shells are subject to an external pressure of 65 Bar due to the difference between outside and inside pressure.In the current paper, 3-D Modelling are carried out as per ASME codes to endure the pressure of $65 \mathrm{Bar}$. At length to thickness ratio of the pressure hull is very large, both 3D shell and 3D solid FEA models were developed and analyzed using Ansys Simulation. The 3D modeling of the assembly has used UNIGRAPHICS software and Finite element analysis is done using ANSYS-Hyper Mesh software.
\end{abstract}

Keywords: Submarine pressure hull, 3-D Pressure hull Model, Hyper mesh, Shell 63 element, Solid 92 element

\section{Introductin About Pressure Hull:}

An AUV ( Autonomous underwater vehicle ) is a robot which travels underwater without requiring input from an promoter. AUVs comprise a part of a massive group of undersea systems known as unmanned underwater vehicles, a category that includes non-independent ROVs ( Remotely operated underwater vehicles ) - controlled and powered from the surface by an pilot/operator via an using remote control or umbilical. In military applications Autonomous underwater vehicle (AUVs) more often referred to simply as UUVs( Unmanned undersea vehicles ). The first Autonomous underwater vehicle was developed at the Applied Physics Laboratory at the University of Washington from now on 1957 by Bob Francois, Stan Murphy, and later on, Terry Ewart.

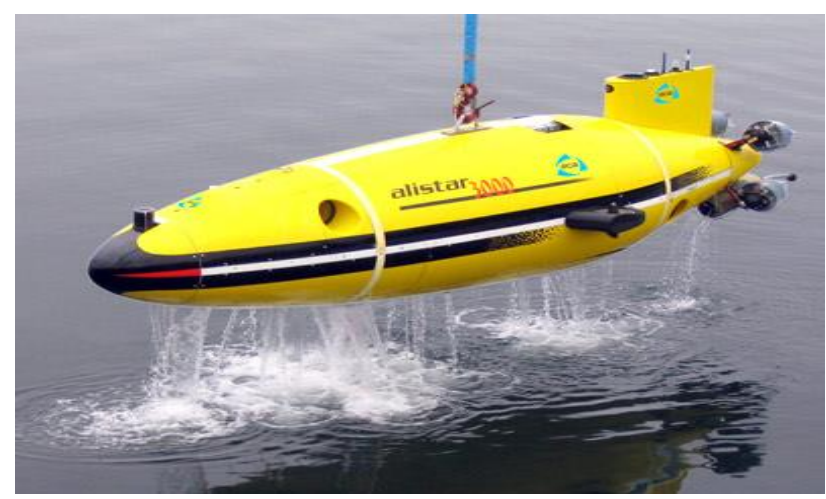

Fig. 1: Modern submarine submarine design is furnished by Arentzen and Mandel [1]. All small modern submarines and submersibles, also the oldest ones, have a sole hull. However, for massive submarines, the approaches have separated. All Soviet heavy submarines are built with a paired hull structure. The term pressure hull can be describe as the inner hull of a submarine, in which approximately standard pressure is maintained when the vessel is immersed.

Submarines are designed to use at great depths. The Hull structure, which is a very important part of the submarine become more and more important since its strength is the main concern. When immersed or submerged, the water pressure on the submarine hull increases while the pressure inside stays the same i.e., one atmospheric pressure McDaniel, [2].

John R. MacKay [3] presented the paper on "Structural Analysis and Design of Pressure Hulls: the State of the Art and Future Trends" which explains that Pressure hulls are the central load bearing structures of naval submarines, research submersibles and autonomous underwater vehicles (AUVs) and commercial. The many similitude between pressure hull, some civil engineering structures, offshore, and aerospace signify that advances in one group are often relevant to the others, and thus this document is sometimes worried with the whole collection of thin-walled curved structures designed for unreliability, referred to hereafter as buckling-critical shells. The modern pressure hull structural analysis and design is accepted in this document by: 1) reviewing novel design procedures for buckling critical shell structures; 2) explaining the nature of structural strength, and associated weaknesses, in pressure hulls; 3) summarizing traditional and contemporary structural analysis and design 
methods for pressure and 4) hulls identifying trends with respect to numerical modeling of buckling-critical shell structures. It is proposed that the layered conservatism of the modern design approach could be enhance by the use of nonlinear numerical methods for strength forecast, and a way forward is suggested that would permit pressure hull design

Liam Gannon [4] presented a paper on "Prediction of the Effects of Cold Bending on Submarine Pressure Hull Collapse" which explains Submarine pressure hull frames and shell plating are shaped by cold bending during fabrication. Cold bending introduces significant residual stress in these components which can be detrimental to the strength of the structure. This study evaluates different methods of consolidate cold bending residual stresses in the evaluation of pressure hulls considering different out of circularity mode shapes. Several methods of pressure hull collapse analysis are compared considering interframe and overall collapse modes. These include an empirical method, a finite difference method and the finite element method. Collapse pressures predicted using the methods prescribed in the UK MoD submarine structure design standard, SSP 74, are found to be conservative when compared with results from finite element analysis. Collapse pressures predicted using effective stress-strain curves to incorporate the consequence of cold bending residual stress an finite element models agree well with those predicted by explicitly modeling the cold bending process. This indicates that the use of effective stress, strain curves is an acceptable means of accounting for the influence of cold bending residual stress of the collapse pressure of a submarine pressure hull.

Finite element is an essential and powerful tool for solving structural problem. FEM can be used for a variety of linear, nonlinear and structural stability problems. FEA package ANSYS is used for modeling by UNIGRAPHICS and analysis for hypermesh of the structure. ANSYS is a general purpose software used for different types of structural analysis mainly for marine structures .It provides a strong pre and post processing tool for hyper mesh generation from only geometry origin to produce almost any element type. Stiffeners are modeled by beam element and cylindrical shell is modeled by shell elements (Paleti Srinivas) et al, [5]. ANSYS hire Newton Raphson approach to resolve nonlinear problem. (Prabu) et al, [6]. In this problem the loads are split up into a sequence of load increments. The load enhancement are applied over several load steps. The iterative process continues until the problem coincide.

\section{Modeling and Simulation}

\subsection{3-D Design and Analysis of Pressure Hull using Hyper Mesh:}

3D model of the pressure hull assembly is as shown in below figure 2. Structural analysis, external pressure of 65bar is applied on the outer surface

-Length overall $=2 \mathrm{~m}$.

-Pressure hull diameter $=0.5 \mathrm{~m}$.

- Layout $=$ Single diameter ring stiffened cylinder with domed ends.

-Submerged displacement $=875$ tonnes .

Initially, structural analysis is carried out by using shell63 element (Quard element), which is a 3D element having 4 nodes and 6 DOF (Ux, Uy, and Uz, Rotx, Roty, and Rotz) at each node. And then, a 3D solid element-Solid92 (Tet element) is used for structural analysis. This element has 10 nodes and 3DOF (Ux, Uy, $\mathrm{Uz}$ ) at each node. After completion of these analyses, we are comparing the results in both the cases. The material used for the construction of the Pressure hull is AH36 steel. The mechanical properties are mentioned below:

Young's Modulus $(\mathrm{Ex})=2.0 \times 10^{5} \mathrm{MPa}$

Poisson's Ratio $=0.3$

Density $=7850 \mathrm{~kg} / \mathrm{mm} 3$

Yield strength $=610 \mathrm{MPa}$

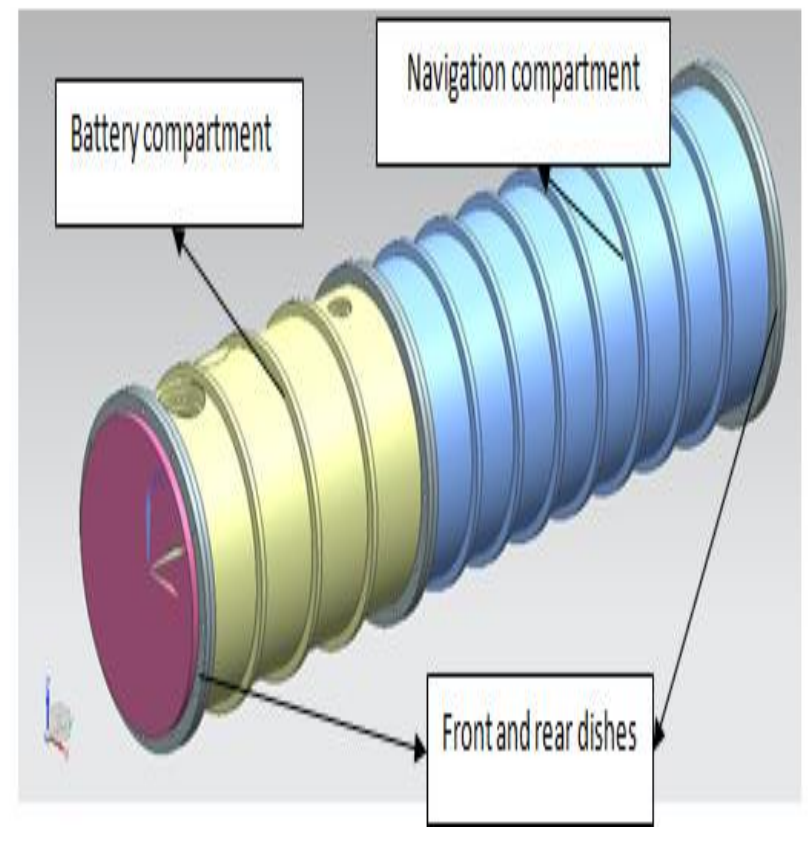

Fig. 2: Assembly of the pressure hull

\subsection{FEA Analysis- HYPER MESH}

General FEA is pre and post processor. Hypermesh is a high execution, and FEA is pre and post processor for majorfinite element and finite element solvers which authorize the engineers to analyze design conditions in a visual environment and highly interactive. Hypermesh 's user interface is easy-peasy to learn to support the direct use of CAD geometry and existing the FEA models providing robust efficiency and interoperability. Advanced automation tools within hypermesh allows users to optimize meshes from a set of quality basis change existing meshes through generate mid surfaces from models of varying thickness and morphing.

\subsubsection{Shell 63 Element:}

SHELL63 has two considered together bending and membrane capabilities. Both normal and in-plane loads are authorized. The element has 6 degrees of freedom at every one node: translations in the nodal $\mathrm{X}, \mathrm{Y}, \& \mathrm{Z}$ directions and rotations about the nodal $\mathrm{X}$, $\mathrm{Y}, \& \mathrm{Z}$-axes. Stress stiffening and large deflection capabilities are covered. A consistent tangent stiffness matrix possibility is available for use in large deflection, and finite rotation analyses. No of Nodes : : 4

No of DOF : : 6 (Ux, Uy, and Uz, Rotx, Roty, and Rotz)

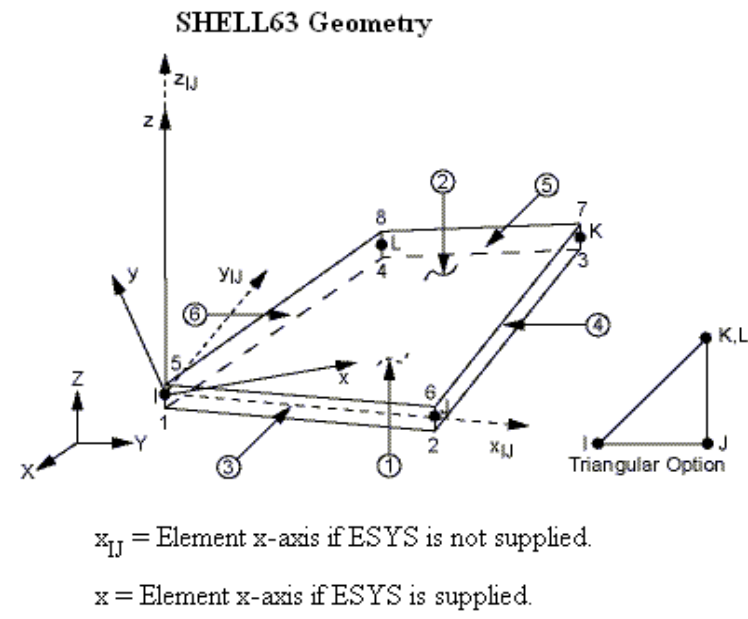

Fig. 3: Geometry of Shell 63 Element 


\section{Input Data:}

The Coordinate system, node locations, and the geometry, for this element are shown in Figure3. SHELL63 Geometry- The element is defined by 4 nodes, 4 thicknesses, an orthotropic material properties, and the elastic foundation stiffness. Orthotropic material directions parallel to the element coordinate directions. The element coordinate system location is as described in Coordinate Systems. The element $\mathrm{x}$-axis may be rotated by an angle ( THETA - in degrees). Number of elements generated in a FEM of the pressure hull using shell 63 element type is 65000 elements, and 1, 23,459 nodes.

\section{Boundary conditions:}

-All DOF is constrained at the both ends.

- The external pressure of 65bar (6.5 MPa) is applied on the areas.

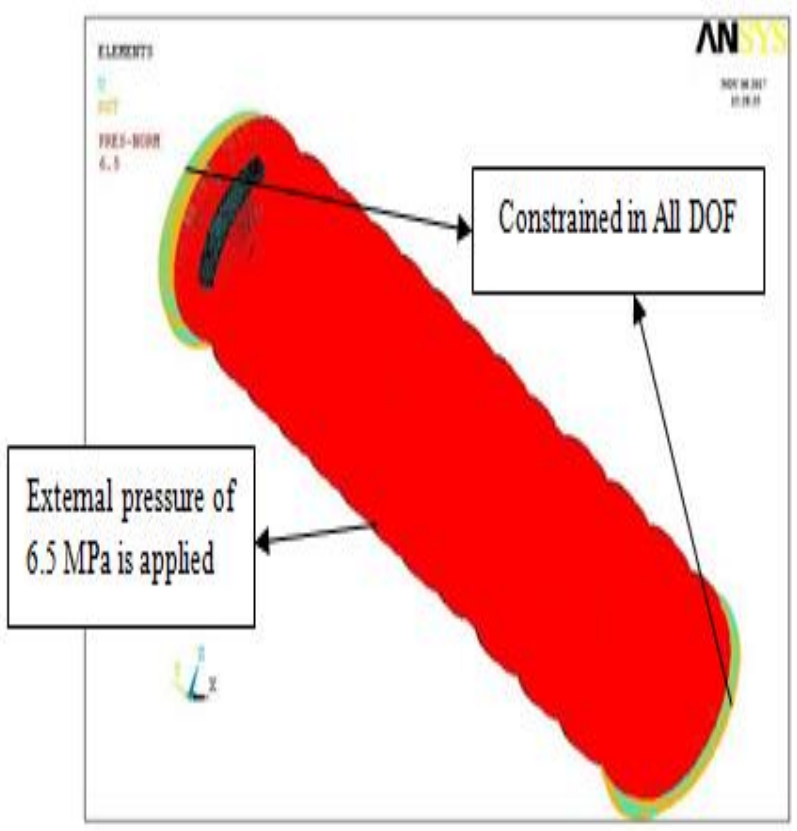

Fig. 4: The above figure shows Mesh type of FEA Model of the pressure hull by using shell 63 Element

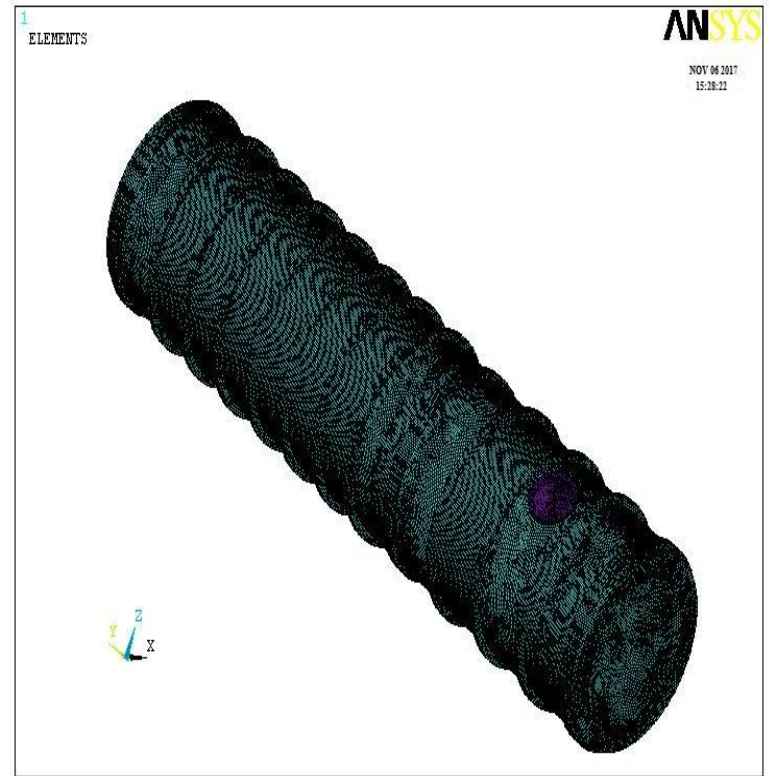

Fig.5: The above figure shows the complete constrained outside of the hull by using Shell 63 Element

\subsubsection{Solid 92 Element:}

An auxiliary to using structural shell elements is the use of continuum, or solid, elements. The element solid92- is defined by 10 nodes having 3 degrees of freedom at each node: translations in the nodal X, Y, \& Z- directions. SOLID92 has a quadratic displacement comportment and is well suited to model asymmetrical meshes.

\section{Input Data:}

Element type : Solid 92

Number. of Nodes: Ten

Degrees of freedom: $3\left(\mathrm{Ux}_{\mathrm{X}}, \mathrm{UY}_{\mathrm{Y}} \& \mathrm{Uz}\right)$

The below figure shows the FEA Model of the pressure hull.
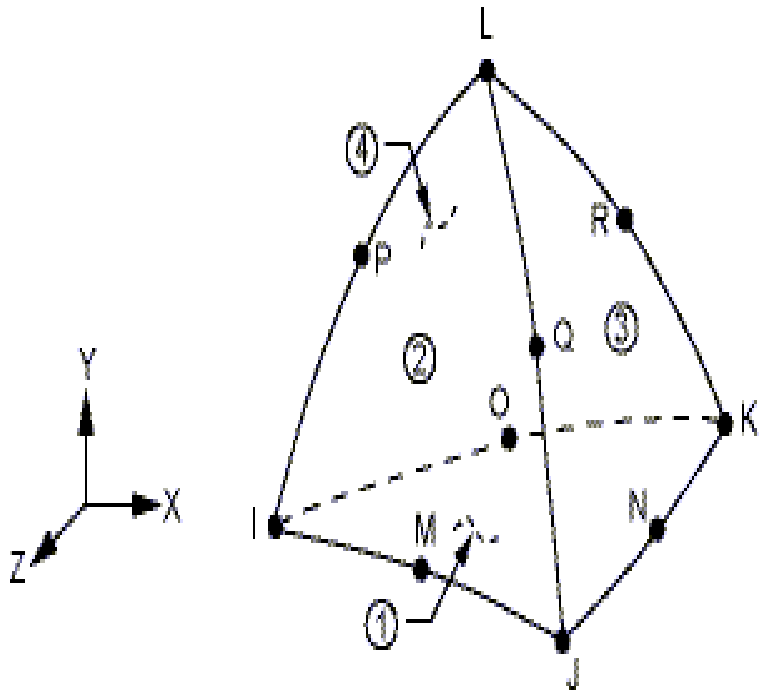

Fig.6: Solid92 geometry

Number of elements generated in a FEA Model of the pressure hull using solid 92 element type is 58576 elements, and 1, 12,876 nodes.

\section{Boundary conditions:}

-All DOF is constrained at the both ends.

- The External pressure of 65bar (6.5 MPa) is applied to the outer areas.

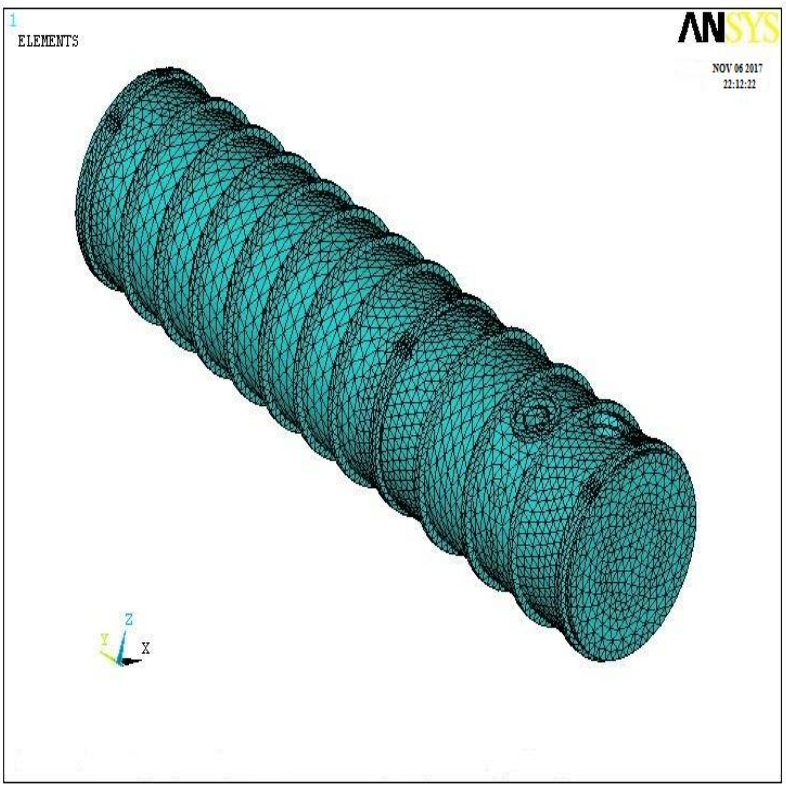

Fig. 7: Mesh type of the Solid 92 Element 


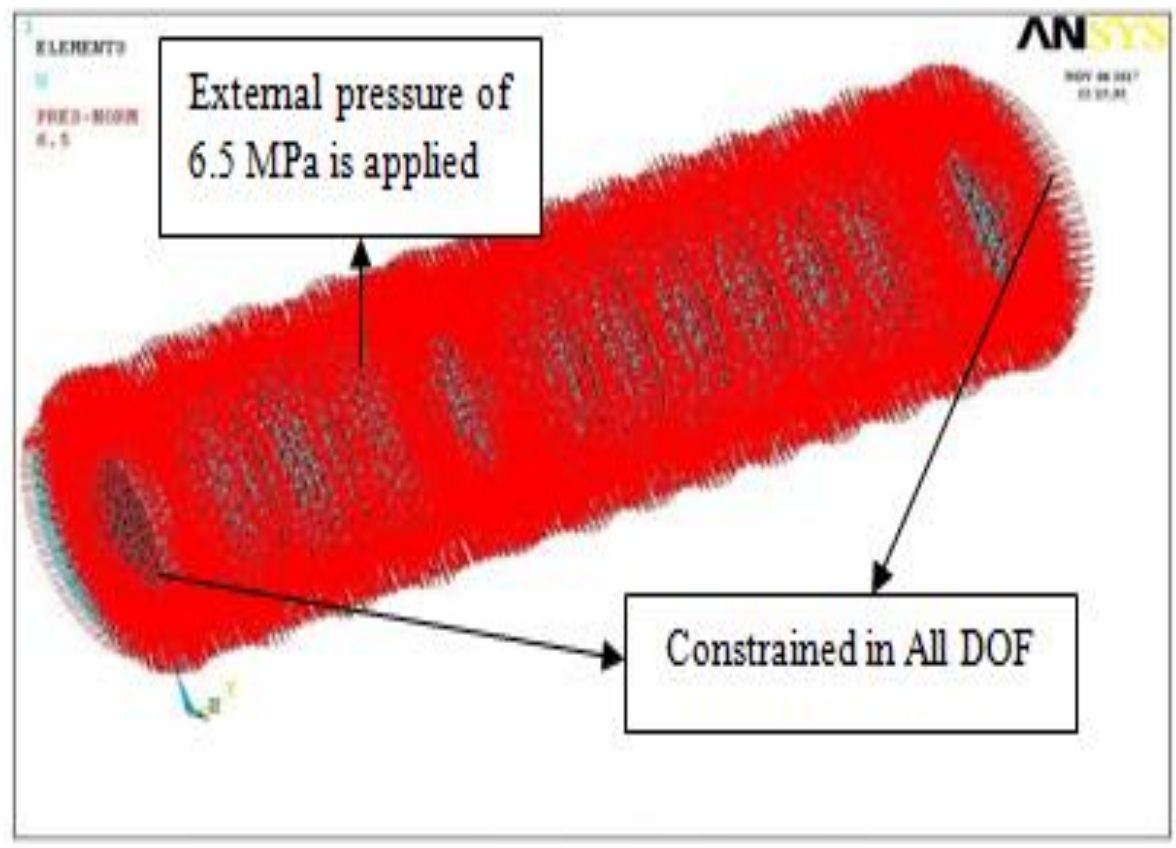

Fig. 8: Solid Mesh with fully Constrained outside by using solid 92 Element

\section{Results and Discussion}

Table 1: Shell 63 Element Vs Solid 92 Element

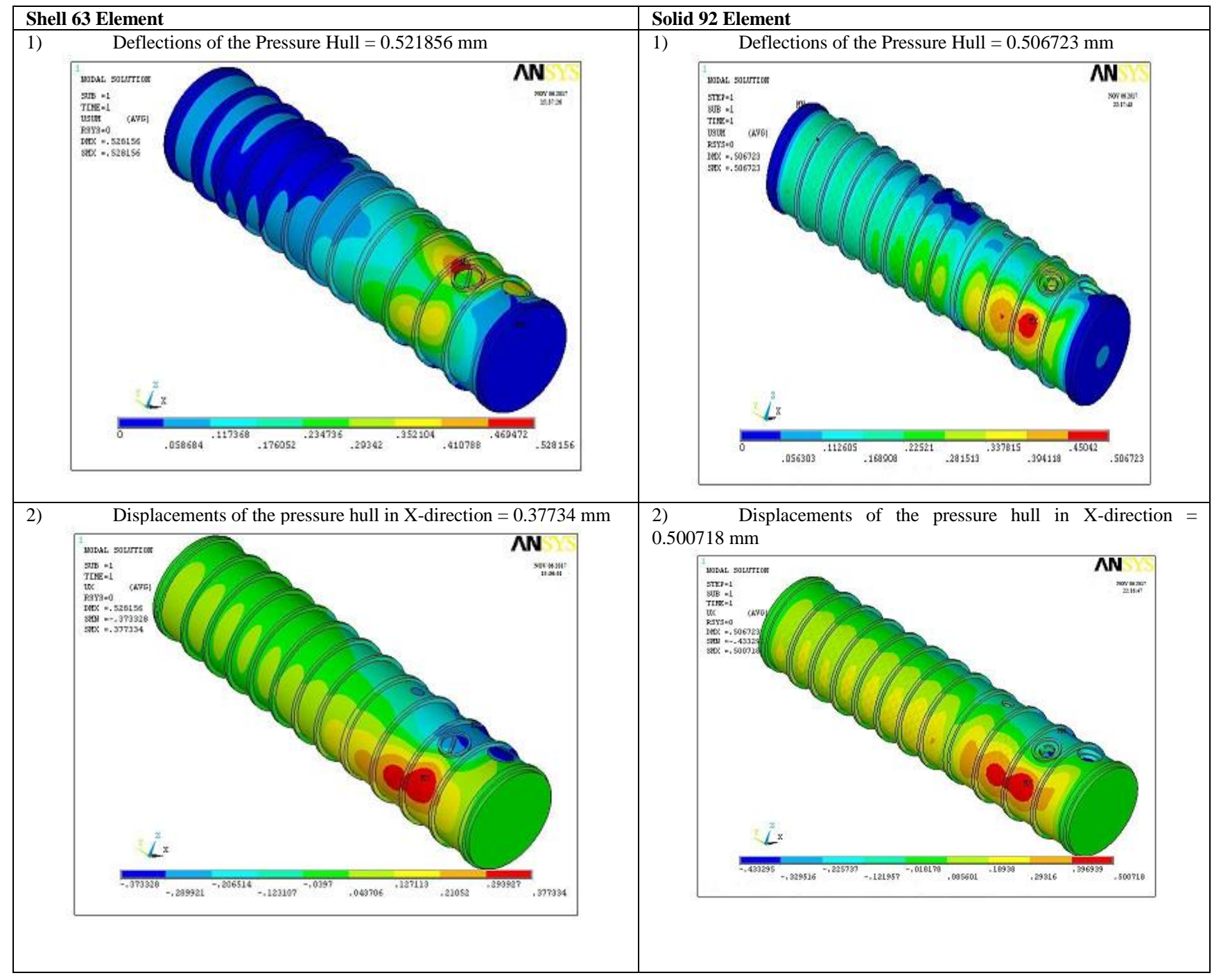




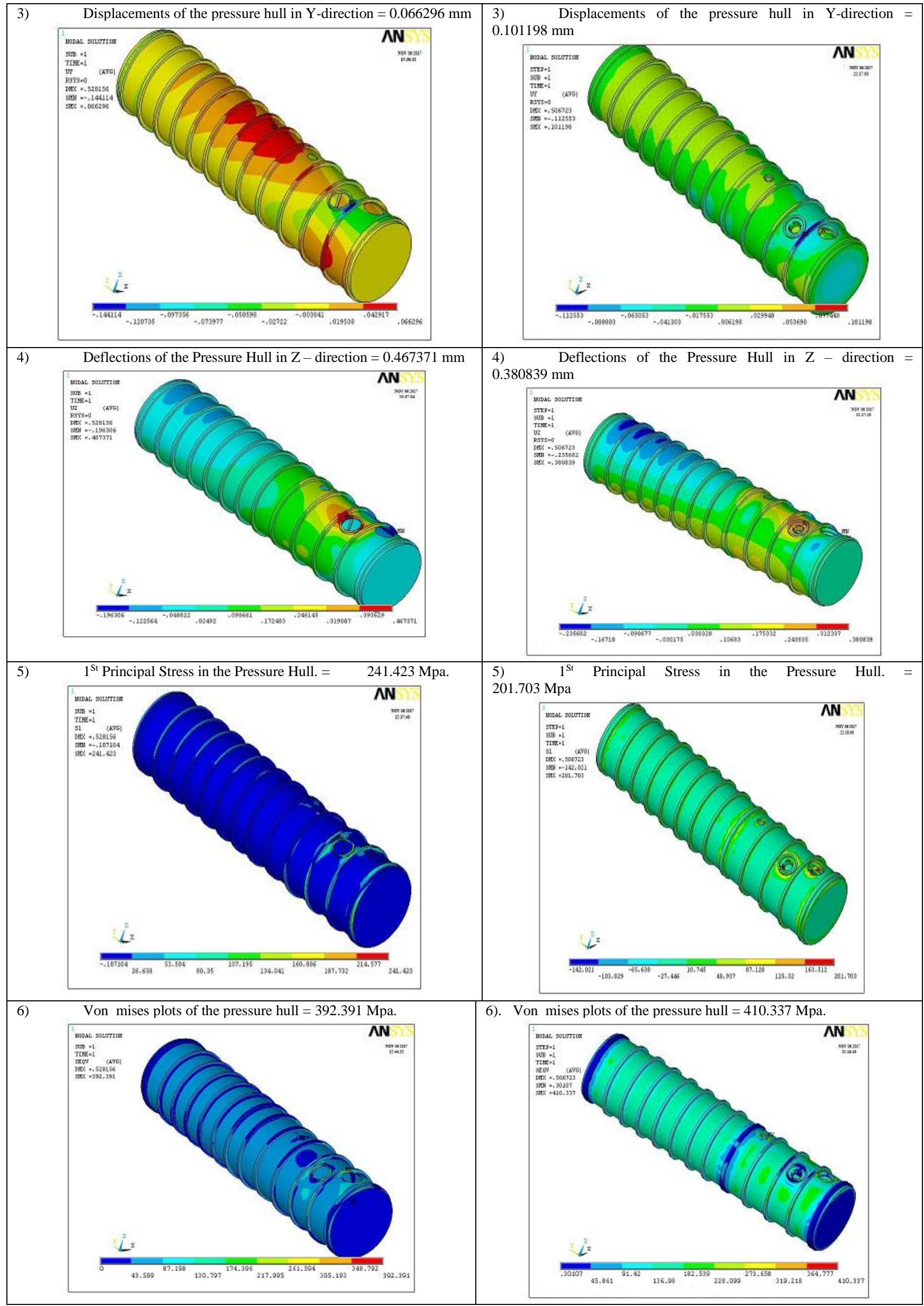




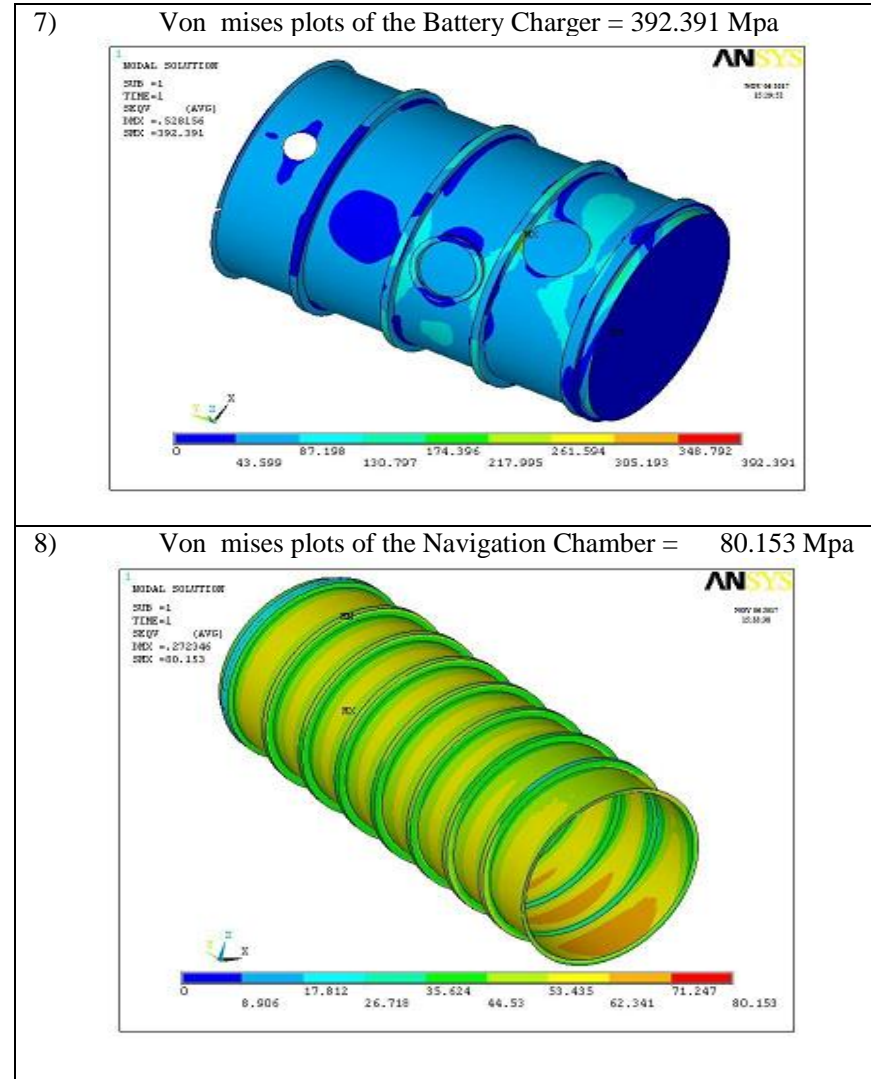

\section{Conclusions}

Structural Analysis is carried out by applying external pressure of 6.5 Mpa. The following results are observed Pressure hull is meshed with shell 63 and solid 92 elements and results are tabulated below.

From the below table 2, Von mises stresses are same in both the cases. These stresses are below the yield strength (610 MPa). So, the design is safe.

Table 2: Results Comparison with Yield strength

\begin{tabular}{|c|c|c|c|}
\hline $\begin{array}{c}\text { Element } \\
\text { Type }\end{array}$ & $\begin{array}{c}\text { USUM } \\
\mathbf{m m}\end{array}$ & $\begin{array}{c}\mathbf{1}^{\text {st }} \text { Principal } \\
\text { Stress MPa }\end{array}$ & $\begin{array}{c}\text { Von mises } \\
\text { stress MPa }\end{array}$ \\
\hline Shell 63 & 0.521856 & 241.423 & 392.391 \\
\hline Solid 92 & 0.56723 & 201.703 & 410.337 \\
\hline
\end{tabular}

\section{References}

[1] Arentzen,E.S, Mandel,P, (1960) 'Naval Architectural Aspects of Submarine Design"' Transaction of SNAME, Vol. 68, pp. 622-692.

[2] McDaniel J T (2011); J T McDaniel Official Website

[3] John R. MacKay "Structural Analysis and Design of Pressure Hulls: the State of the Art and Future Trends" Defence R\&D Canada - Atlantic Technical Memorandum,Oct 2007 pp 1-50

[4] Liam Gannon "Prediction of the Effects of Cold Bending on Submarine Pressure Hull Collapse" Defence R\&D Canada Atlantic Technical Memorandum, April 2010 pp 1-31

[5] Paleti srinivas, Krishnachaithanya Sambana, Datti Rajeshkumar (2010) "Finite element analysis using ANSYS.11.0." e book, Publisher PHI Learning Pvt Ltd, pp 1-528

[6] Prabu N, Rathinam N,Srinivasan R,Narayanan K A S ( 2009) "Finite Element Analysis of buckling of thin cylindrical shell subjected to uniform external pressure" Journal of Solid Mechanics V 1, No. 2 pp 148-158.

[7] Rajesh, M., and J. M. Gnanasekar. \&quot;Congestion control in heterogeneous wireless ad hoc network using FRCC.\&quot; Australian Journal of Basic and Applied Sciences 9.7 (2015): 698702.

[8] S.V.Manikanthan and T.Padmapriya "Recent Trends In M2m Communications In 4g Networks And Evolution Towards 5g",
7). Von mises plots of the Battery Charger $=410.337 \mathrm{Mpa}$

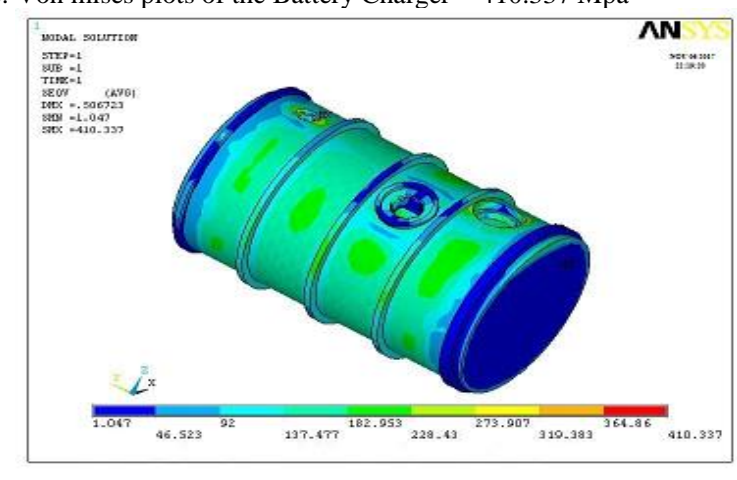

8). Von mises plots of the Navigation Chamber $=282.034 \mathrm{Mpa}$

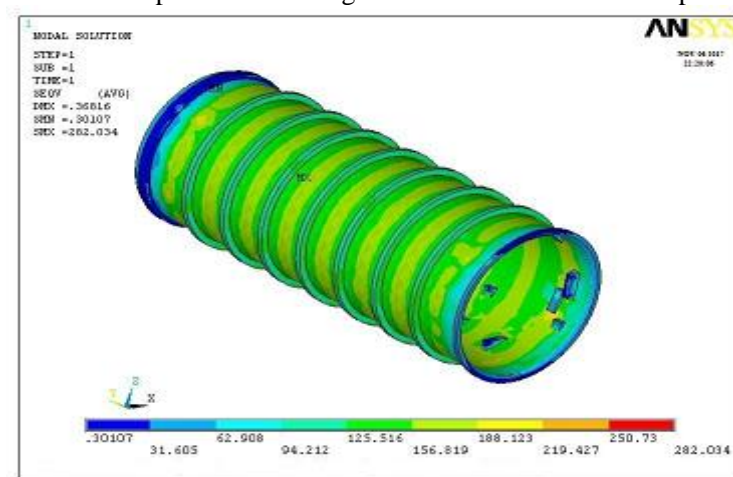

International Journal of Pure and Applied Mathematics, ISSN NO:1314-3395, Vol-115, Issue -8, Sep 2017.

[9] S.V.Manikanthan and K.srividhya "An Android based secure access control using ARM and cloud computing", Published in: Electronics and Communication Systems (ICECS), 2015 2nd International Conference on 26-27 Feb. 2015,Publisher: IEEE,DOI: 10.1109/ECS.2015.7124833.

[10] T. Padmapriya, V.Saminadan, "Performance Improvement in long term Evolution-advanced network using multiple imput multiple output technique", Journal of Advanced Research in Dynamical and Control Systems, Vol. 9, Sp-6, pp: 990-1010, 2017. 